\title{
O RESGATE DO PROCESSO DO “CUIDADO DE SI” COM MULHERES INSERIDAS NO CONTEXTO DE VIOLÊNCIA DOMÉSTICA
}

\author{
Leila Platt Deeke ${ }^{1}$, Elza Berger Salema Coelho², Fátima Buchelle ${ }^{3}$, Antonio Fernando Boing ${ }^{4}$
}

RESUMO: Este artigo apresenta um estudo sobre o resgate do processo do "cuidado de si" com mulheres inseridas no contexto de violência doméstica. Esta proposta foi desenvolvida por meio de uma prática assistencial justificada pelo interesse em realizar prevenção seletiva ao abuso de drogas e direcionada a seis mulheres submetidas à violência física no lar. Os dados foram obtidos mediante entrevista semi-estruturada, de março a maio de 2004 e analisados segundo dois eixos temáticos conforme proposto por Bardin: 'Conhecendo o outro por meio da escuta' e 'o cuidado de si por meio do diálogo'. Para suportar o desconforto psicológico, estas mulheres ingerem os ansiolíticos com a expectativa de que os seus efeitos aplacarão as emoções negativas desencadeadas pela violência. Foi importante incentivar às mulheres na identificação das condutas e situações de risco e funções atribuídas à droga no contexto de violência doméstica. PALAVRAS-CHAVE: Violência contra a mulher; Violência doméstica; Transtornos relacionados ao uso de substâncias.

\section{THE RESCUING PROCESS OF WOMEN'S SELF CARE WITHIN A CONTEXT OF DOMESTIC ABUSE}

\begin{abstract}
This article presents a study on the rescue process of self care with women in a domestic violence context. This proposal was developed by means of a caring practice justified by the interest in carrying out selective prevention from drug abuse and directed to six women submitted to domestic abuse. The data collection was effected through a semi-structured interview, from March to May of 2004 and analyzed according to two thematic axles proposed by Bardin: 'Knowing the other through listening' and 'self care through dialogue'. Those women take ansiolitics in order to cope with the psychological distress and expecting to reduce the negative emotions triggered by violence. It was important encourage such women in the identification of risk behaviors and situations as well as the drug functions in that context of domestic abuse.
\end{abstract}

KEYWORDS: Violence against women; Domestic abuse; Substance related disorders.

\section{EL RESCATE DEL PROCESO DEL “CUIDADO DE SÍ” COM MUJERES INSERIDAS EN CONTEXTO DE VIOLENCIA DOMÉSTICA}

RESUMEN: Este artículo presenta un estudio acerca del rescate del proceso de "cuidado de si" en mujeres que habitan en contexto de violencia doméstica. Esta propuesta fue desarrollada a través de una práctica asistencial cuyo objetivo era realizar una prevención selectiva del abuso de drogas que se dirigía a seis mujeres sometidas a violencia física en sus hogares. Los datos fueron obtenidos a partir de una entrevista semiestructurada, aplicada entre marzo y mayo de 2004 e analizados según dos ejes temáticos de acuerdo con la propuesta de Bardin: "Conociendo al otro por médio de la escucha" y "El cuidado de sí por medio del diálogo". Para soportar el sufrimiento psicológico, estas mujeres injieren ansiolíticos con la expectativa de que sus efectos ayuden en las emociones negativas desencadenadas por la violencia. Fue importante incentivar a las mujeres a identificar conductas e situaciones de riesgo, así como las funciones atribuidas a la droga en ese contexto de violencia doméstica.

PALABRAS CLAVE: Violencia contra la mujer; Violencia doméstica; Transtornos relacionados con substancias.

${ }^{1}$ Mestranda do Programa de Pós-Graduação em Saúde Publica da Universidade Federal de Santa Catarina - UFSC.

${ }^{2}$ Professora Doutora do Programa de Mestrado em Saúde Pública do Departamento de Saúde Pública da UFSC. Líder do Grupo de Pesquisa Saúde da Mulher e Políticas Públicas.

${ }^{3}$ Professora Doutora do Programa de Pós-Graduação em Saúde Pública do Departamento de Saúde Pública da UFSC.

${ }^{4}$ Doutorando do Programa de Pós-graduação em Ciências Odontológicas - Universidade de São Paulo - USP.

Autor correspondente:

Leila Platt Deeke

Rua Santo Amaro, 279 - CEP 88075-510 - Florianópolis - SC

Recebido em: 19/04/07

E-mail: leiladeeke@hotmail.com 


\section{INTRODUÇÃO}

O cuidado com a saúde biopsicossocial de indivíduos revela-se como prática e pesquisa do campo da Saúde Coletiva, que por sua vez é caracterizado por integrar em seu bojo profissionais de diversas especialidades. Estes, atualmente, reconhecem-se inseridos neste setor com visões e objetivos cada vez mais específicos, porém, empenhados em prol de um bem comum: identificar e compreender as necessidades de cuidado em saúde da coletividade. Para tanto, visam elaborar estratégias para que este cuidado resulte na promoção de uma melhor qualidade de vida e bem-estar para esta coletividade. Com esta idéia da valorização da interdisciplinaridade em Saúde Coletiva, ressalta-se que "da matemática às ciências sociais descortina-se ampla gama de campos de pesquisa os quais, em última análise, interessam à saúde pública na sua participação para a melhoria da qualidade de vida"(1:87).

Em âmbito mundial, foi na década de 1990 que oficialmente o setor saúde começou a assumir os acidentes e a violência não apenas como uma questão social, mas como de grande importância no campo de pesquisa na área da saúde coletiva. Tal valorização ocorreu em decorrência do impacto que provocam na qualidade de vida e pelas lesões físicas, psíquicas e morais que acarretam e pelas exigências de atenção e cuidados dos serviços médico-hospitalares. Além disso, pela concepção ampliada de saúde, em que a violência é objeto de intersetorialidade, na qual o campo médico-social se integra ${ }^{(2)}$.

A violência concerne atualmente à nova perspectiva que busca se consolidar como linha de pesquisa no campo da saúde coletiva, articulando as tecnociências com as ciências humanas, integrando as dimensões coletivas e individuais, objetivas e simbólicas, quantitativas e qualitativas ${ }^{(3)}$.

A violência contra a mulher é considerada pela Organização Mundial da Saúde como um problema prioritário de Saúde Pública ${ }^{(4)}$ e passou a ser oficialmente reconhecida a partir da Declaração Sobre a Violência Contra a Mulher, aprovada pela Conferência dos Direitos Humanos em Viena, no ano de 1993, como

todo ato de violência de gênero que resulte em ou possa resultar em dano ou sofrimento físico, sexual ou psicológico da mulher, incluindo a ameaça de tais atos, a coerção ou a privação arbitrária da liberdade, tanto na vida pública como na vida privada ${ }^{(5: 3)}$.

O fenômeno da "violência contra a mulher" se traduz em diversas repercussões para a qualidade de vida e saúde para as mesmas. Verifica-se que a violência conjugal e o estupro têm sido associados a maiores índices de suicídio, queixas vagas, cefaléia, distúrbios gastrointestinais, sofrimento psíquico em geral e sobremaneira ao abuso de álcool e outras drogas. No que diz respeito à saúde reprodutiva, a violência contra a mulher tem sido associada às dores pélvicas crônicas, às doenças sexualmente transmissíveis, como a síndrome da imunodeficiência humana adquirida (AIDS), além de doenças pélvicas inflamatórias, abortos e gravidez indesejada ${ }^{(6)}$.

As queixas de agressões físicas e ameaças efetuadas por mulheres em Delegacias Especializadas de Atendimento à Mulher (DEAMs) contra seus parceiros, denunciam uma forma de solicitação de ajuda, um pedido de socorro num lugar em que procuram serem cuidadas e confortadas. A obtenção de conforto por parte das solicitantes inclui a habilidade de confiarem, de serem apoiadas, de obterem esperanças e forças para enfrentarem a realidade com autonomia ${ }^{(7)}$.

Entretanto, há uma preocupação com mulheres que retornam a solicitar ajuda à delegacia, queixando-se de ameaças e/ou agressões físicas por parte do parceiro, sendo o conteúdo destas queixas o mesmo de outras ocasiões. Quando ocorre este tipo de circunstância, parece haver um entrave por parte da mulher no que diz respeito ao reconhecimento de sua participação em sua autonomia, de cessar o processo de ameaças e/ou agressões físicas.

Diante desse panorama complexo, desponta a imperiosa necessidade de ações tendentes à reversão do quadro da violência contra a mulher. Existe uma preocupação do ser humano em entender o fenômeno de violência "a fim de atenuá-la, preveni-la e eliminála da convivência social"(2:7), pretensão esta que pode parecer elevada demais, para não dizer inalcançável e inatingível ${ }^{(8)}$. Há, entretanto, uma série de atividades que poderiam e deveriam ser postas em prática com vistas à sua redução ou a redução de seus danos.

Levando o exposto em consideração, este artigo apresenta um estudo sobre o resgate do processo do "cuidado de si" com mulheres inseridas no contexto de violência doméstica, a partir de uma prevenção seletiva ao abuso de drogas.

\section{OS CAMINHOS PARA O RESGATE DO PROCESSO DO CUIDADO DE SI}

O presente estudo efetivou-se por meio de 
uma ação de prevenção seletiva ao uso abusivo de drogas, direcionado a seis mulheres submetidas à violência física no ambiente doméstico pelo parceiro. Elas apresentavam idades variando entre vinte e cinco e cinqüenta e dois anos e com níveis de escolaridade entre o ensino fundamental e médio.

Foram realizadas entrevistas semiestruturadas entre os meses de março a maio de 2004 e as respostas anotadas em planilhas pela pesquisadora. As mulheres foram selecionadas na Delegacia de Polícia de Proteção à Mulher, à Criança e ao Adolescente $-6^{a}$ DP de Santa Catarina - com o intento de que dois fatores essenciais estivessem permeando o contexto de violência destas mulheres: o uso de substâncias psicoativas por parte do parceiro e ter havido três ou mais queixas-crimes da agredida na Delegacia de Proteção à Mulher.

A definição de prevenção seletiva ao uso de drogas é caracterizada por dirigir-se a subgrupos da população geral, normalmente pessoas de maior risco; possui como objetivo atrasar ou prevenir o abuso, detectando os fatores de risco para combatê-los. Os participantes são recrutados e entende-se que todos são vulneráveis ${ }^{(9)}$.

A proposta para o resgate do "cuidado de si" com estas mulheres - apresentadas ficticiamente neste trabalho como Sandra, Luciane, Telma, Laura, Ilda eAna - foi baseada na idéia de que para cada contexto ou dimensão social existem situações de possível intervenção para a transformação do cuidado prestado a essas pessoas. Não esquecendo de que a transformação global se dá pelo somatório das ações locais, sendo este, o espírito da horizontalização das ações de cuidado em saúde coletiva que, por sua vez, é uma decorrência lógica, um corolário do movimento social vigente ${ }^{(10)}$.

Para análise dos dados utilizamos etapas da análise de conteúdo proposta por Bardin ${ }^{(11)}$, na qual definimos dois eixos temáticos: 'Conhecendo o outro por meio da escuta' e 'O cuidado de si por meio do diálogo'. Os eixos foram definidos tendo como base as etapas denominadas de Avaliação Inicial e Simples Aconselhamento. Estas etapas são oriundas da técnica canadense "Intervenções Breves (Brief Intervention)" no tratamento do uso de drogas psicoativas, inserida no Brasil em 1987 pela Doutora Martha Sanchez Craig e publicada em 1992 na obra "A intervenção breve na dependência das drogas: a experiência brasileira" por Maria Lúcia Formigoni et $\mathrm{a}^{(12)}$. As d as etapas foram utilizadas com adaptações, sen lo as demais presentes na formulação original - Avaliação Cognitiva, Avaliação Laboratorial, Psicoterapia de Grupo, Seguimento da Avaliação não efetuadas nesta prática assistencial pelo fato de este trabalho dedicar-se a uma intervenção breve preventiva com curto espaço de tempo, ao uso indevido de drogas e não à um tratamento.

Deste modo, esta prática assistencial constituiuse de duas entrevistas realizadas pela pesquisadora, em intervalo de tempo de quinze a trinta dias com cada uma das seis mulheres. Na primeira entrevista, denominada Avaliação Inicial foram abordados três itens: os determinantes do contexto social mais amplo do sujeito da prática assistencial (condições de vida, condições culturais, ocupacionais, geográficas, motivacionais - um conjunto de condições que concorrem com a situação de violência doméstica); os aspectos individuais em relação à violência doméstica (dinamismos intrapessoais ativados nesta situação específica, modalidades defensivas pessoais seletivamente mobilizadas pela situação, recursos adaptativos); e os aspectos relativos à violência doméstica e ao abuso de drogas (abrangendo aspectos históricoindividual-grupais e sociais do homem autor da agressão e de sua respectiva parceira vítima de agressão).

Para a completa execução da Avaliação Inicial foram efetuados os seguintes passos: a) a necessária comunicação com cada uma das mulheres contactadas por telefone, explicando tratar-se de um projeto com o intuito de saber como estava a qualidade física e psicológica das mesmas diante da violência exercida no ambiente familiar despertando o interesse de uma entrevista inicial utilizando as dependências da Delegacia. Neste primeiro contato, ao telefone, três atributos da intervenção preventiva foram mencionados: sigilo, brevidade e flexibilidade (em termos da escolha de horários, permitindo à mulher em questão não interromper suas atividades profissionais e familiares); b) a utilização das Dependências da Delegacia da Mulher como local para a realização da Avaliação Inicial. Apenas uma entrevista foi realizada no consultório da entrevistadora em decorrência de dificuldades geográficas e de transporte por parte da entrevistada em se deslocar até a Delegacia e c) ao final de cada Avaliação Inicial foi combinado com cada uma das entrevistadas que, num intervalo de 15 a 30 dias, a psicóloga voltaria a entrar em contato para marcarem um novo encontro.

Para a completa execução da etapa Simples Aconselhamento foram efetuados os seguintes passos: a) a comunicação necessária com cada uma das mulheres selecionadas por meio de telefone. Foi 
combinado um segundo encontro com o intuito de iniciar a nova etapa do trabalho e saber como estavam os andamentos das metas e planos estabelecidos por elas (mulheres) a partir do primeiro encontro reflexivo; b) a realização do Simples Aconselhamento no domicílio das mulheres selecionadas. Esta escolha foi devido à inviabilidade das dependências da Delegacia na semana em que o Aconselhamento havia sido combinado com as participantes. Como exceção, dois aconselhamentos foram realizados no consultório da entrevistadora. Um por periculosidade devido à agressividade do cônjuge e o outro por dificuldades geográficas em chegar ao domicílio da entrevistada.

$$
\mathrm{Na} \text { segunda entrevista (Simples }
$$

Aconselhamento) foram utilizadas três estratégias para a prevenção seletiva, a saber: auxiliar as mulheres a auto-observarem suas condutas de risco para o combate de um futuro abuso indevido de drogas; incentivá-las a como lidar efetivamente com as situações de risco para um possível abuso de drogas e com as dificuldades de se engajar em novas atividades e metas; e apoiá-las em suas tentativas de retomar iniciativas interrompidas, responsabilizando-as pelas possíveis mudanças.

Os instrumentos didáticos utilizados no momento da Avaliação Inicial e do Simples Aconselhamento, por se tratar de uma prática assistencial, foram somente uma caneta para pertinentes anotações e roteiro a serem seguidos no momento das entrevistas.

Após a realização dos encontros reflexivos, as mulheres envolvidas assinaram um Termo de Consentimento Livre e Esclarecido concordando que os resultados fossem publicados contanto que seus nomes e imagem estivessem salvaguardados. A pesquisa foi aprovada pelo Comitê de Ética em Pesquisa da Universidade Federal de Santa Catarina sob o parecer $n^{\circ}$ 246/06, atendendo à Resolução 196/ 96 do Conselho Nacional de Saúde.

\section{CONHECENDO O OUTRO POR MEIO DA ESCUTA}

A noção de cuidado em saúde é um processo de interações e associações entre os seres, sendo parte organizadora do sistema de saúde, parte do sistema de cuidados, co-organizando-se com os demais sistemas sociais. "No nível individual, o cuidado deve se revelar no autoconhecimento e no conhecimento do outro, conhecer limites e possibilidades e aprender a respeitá-lo em si mesmo e no outro"(13:479).

A percepção da diversidade cultural nas maneiras de ver e viver a saúde-doença, prevenção e cura pelas diferentes coletividades, grupos e sujeitos é imprescindível na qualificação das instituições, das inter-relações, na identificação de necessidades e nos resultados obtidos ${ }^{(14)}$. Entretanto, similarmente, não se pode investir na adoção de estilos de vida mais saudáveis e práticas de autocuidado sem levar em consideração a questão da intersubjetividade em fatores que a compõem, tais como:

valores, conceitos, prazeres, medos, vontades, desejos conscientes e inconscientes; uma vez que os modos de agir e cuidar-se em saúde não se desvinculam do universo cultural e psico-emocional dos sujeitos, sendo esses vistos como seres mais que racionais e auto-regulados ${ }^{(15: 669)}$.

Abrir-se às histórias de vida, às intersubjetividades, aos mecanismos de submissãoresistência presentes na atenção, compreendendo-os e atuando nesses campos, requer a construção de aprendizagens conjuntas e acordos, em que os sujeitos envolvidos na inter-relação, interroguem-se conjuntamente sobre onde chegar e como, mediante uma tecnologia básica - o diálogo.

O diálogo constrói-se com base na escuta, na interpretação dos significados contextuais e subjetivos presentes nas manifestações, mediada neste contexto de prática assistencial, pelas palavras, pelos gestos e pelo olhar. Desse modo, assume-se o diálogo não somente como uma escuta bem intencionada, com a intenção de apoiar o outro, mas como interlocução fundada em eixos que considerem a complexidade dos envolvidos, os seus processos interacionais e a vida tal como vivida e percebida. Esta escuta é compreendida a partir da associação ao ato de despirse da armadura do conhecimento técnico-científico e de dispor-se a ouvir o outro como alguém que sabe algo sobre o mundo e sobre si mesmo ${ }^{(16)}$.

Diante do exposto e a partir da convicção de que cada pessoa ao longo de sua existência cresce em sua capacidade de expressar cuidado consigo e com os outros e de que o cuidado é um processo e como tal se desdobra continuamente é que foi possível estar presente à totalidade das experiências vividas por Sandra, Luciane, Laura, Telma, Ilda e Ana e, por conseguinte, ouvir os pedidos de cuidado e de respondê-los a fim de que se desse o início do resgate do processo do cuidado de si com estas mulheres. $\mathrm{O}$ momento de cuidado compreende-se como sendo um campo existencial energético, um ponto decisivo, um chamado para as mais elevadas e profundas 
consciência e intencionalidade, uma escolha autêntica de cuidar/viver ${ }^{(17)}$.

A partir do compartilhamento no encontro reflexivo das experiências vividas pelas mulheres com o perfil delineado na prática assistencial, pôde-se constatar que muitas vezes para suportar a angústia pessoal e o desconforto psicológico elas utilizam especialmente os tranqüilizantes e ansiolíticos como forma de automedicação, se configurando como "uma muleta até se recuperar". Para Sandra, há a expectativa de que os efeitos de tais substâncias a ajudará a suportar a sensação de baixa-estima, impotência e outras emoções negativas diante da violência física, verbal e emocional exercida pelo parceiro no âmbito intrafamiliar.

Poderíamos formular várias hipóteses com o intuito de questionar os motivos pelos quais estas mulheres suportam permanentemente os sentimentos negativos provenientes da violência doméstica, uma vez que já prestaram mais de três queixas na Delegacia de Proteção à Mulher contra agressões e/ou ameaças dos parceiros. Uma das possibilidades é de que há casais que se perpetuam num vínculo de ódio, desprezo mútuo, ataque, maus-tratos e esses relacionamentos funcionam como instrumentos de tortura e auto-tortura.

Em relação ao uso de álcool e/ou outras drogas pelos parceiros, este fator pareceu influenciar na conduta violenta, provavelmente por interferir nos padrões de comportamento facilitando a violência, uma vez que acentuou o desequilíbrio de controle e poder exercidos pelos mesmos sobre as mulheres. Os verdadeiros mecanismos responsáveis por essa associação, drogas e comportamento violento, ainda estão por ser desvendados, não estando evidente se as substâncias psicoativas funcionam como um fator causal direto ou indireto, ou ainda, como um modificador do efeito de outros fatores ${ }^{(18)}$.

Contudo, é importante enfatizar que a violência física, verbal e psicológica perpetradas pelos parceiros no lar, como foram percebidas nas histórias de vida de Luciane, Telma e Laura, não eram somente os únicos fatores de risco para que as mesmas procurassem o efeito de alívio que as substâncias psicoativas provocam. Uma vez que, fatores de riscos como abuso sexual na infầncia e na adolescência, privação econômica, fracasso escolar, história familiar de alcoolismo, de violência doméstica e prostituição podem estar contribuindo para que a insônia, a depressão e a angústia exacerbada venham à tona mascarados pela violência intraconjugal.

Deste modo, percebemos que por vezes permanecer com um cônjuge problemático traz ganhos secretos tão importantes que, no fundo, a pessoa deseja manter exatamente a situação da qual se queixa. Se for o outro que está com problemas, fica mais fácil a pessoa fechar os olhos aos seus sintomas. Nesse sentido,

a doença está no outro e a pessoa fica a salvo [...]. As doenças são, muitas vezes, a única expressão possível de outros problemas, conflitos e insatisfações crônicas. As pessoas não ousam encarar as reais dificuldades e vivem à procura de tratamentos para os sintomas, sem cuidar da gênese da problemática: tomam remédios para a dor de cabeça, tranqüilizantes para dormir e adormecer a consciência de tudo aquilo que não vai bem ${ }^{(19: 43-5)}$.

Evidenciamos a dificílima tarefa do desvencilhamento do circuito violento por parte das mulheres. Ficou evidente que a associação entre a violência e a utilização de drogas pelo parceiro conduz algumas mulheres a pensarem que a droga é um elemento à parte da vida do cônjuge e não constituinte, atribuindo o uso de substâncias psicoativas como parte alheia da história de vida do mesmo. Conforme relato de Ilda, a seguir:

Tenho esperança de ser feliz com ele e de que um dia ele vai parar de beber [...] é honesto, é bom [...] o que estraga é a bebida; com a bebida ele é agressivo e ignorante. E fora da bebida é diferente. Ele é honesto. Tudo o que eu peço ele faz, a bebida é que estraga; se transforma em outra pessoa.

O fato acima exposto é pertinente para explicar alguns fatores percebidos nos relatos das mulheres sobre as razões que, mesmo sofrendo fisicamente e psiquicamente com a violência doméstica, continuam mantendo a relação conjugal, um dos fatores poderiam ser as características do amor difícil que é a sua absoluta irregularidade, confirmada com o comentário de Telma ao ressaltar:

Ele é um homem muito bom, e só é agressivo quando usa drogas e que a única força que a faz ficar junta dele é a esperança que ele pare de usar drogas.

A fala de Telma vai ao encontro da afirmação:

Se o amado fosse sempre uma peste, sempre bêbado, sempre agressivo ou sempre rejeitador, cedo nos cansaríamos. Mas ele alterna, joga, vai e vem, mantendonos sempre alerta, com o coração na mão. E jogandonos de lá pra cá, entre o seu querer e o seu negar, vai aos poucos aplastrando nossa vontade, deixando-nos quase à deriva, num ritmo que não é nosso ${ }^{(20: 162)}$. 
O outro fator identificado seria a existência de mulheres que preferem continuar no horror conhecido,

um casamento infeliz arrastado indefinidamente costuma representar o núcleo mórbido das pessoas, instalando uma depressão crônica, uma angústia de não se sabe o quê, a sensação de suicídio lento $[\ldots]^{(19: 45)}$.

Histórias compartilhadas de vida, como a de Telma, Laura e Ana, demonstram que há mulheres que seguem anos a fio acumulando mágoa e rancor e freqüentemente adoecendo. Deste modo, a mulher transforma-se em sofredora, contudo, segue a mesma trajetória como única alternativa. Durante anos ameaça ou planeja separar-se, ensaiando permanentemente a separação. "Comumente, essa atitude refere-se, entre outras coisas, à dificuldade de lidar com a própria raiva, hostilidade ou violência, sob o medo de machucar o outro ou fazê-lo sofrer"(19:40). Este fato foi exemplificado pela história de Ana que, apesar de querer separar-se devido às humilhações e agressões realizadas pelo parceiro, conseguia e interrogava a si mesma:

[...] agora o que é que vai acontecer é que mais uma vez para eu não me separar..?

Ela coloca o motivo da não separação em causas exteriores. No final da entrevista Ana afirma realmente estar angustiada, pois tem

\section{[...] pena que ele possa ficar muito mal se ficar sozinho.}

Esta incerteza percebida nos relatos faz com que as mulheres perpetuem um sofrimento imposto a si e ao cônjuge quando se mantém um casamento que não atende às necessidades de auto-realização. A história de vida compartilhada por Ana foi esclarecedora de que o medo de fazer sofrer pode ser apenas a capa do medo de expandir-se, "de trocar a segurança da estabilidade pelo imprevisível da liberdade"(19:40).

Diante do exposto, a análise dos discursos das mulheres no encontro reflexivo trouxe à tona a eterna questão: a díade entre o desejo de mudar e a resistência à mudança. A conscientização por parte das mulheres de que é preciso reunir forças e se refazer para o processo de mudança, reavaliando os prós e os contras para uma futura qualidade de vida, realmente não é tarefa fácil, pois como mudar uma realidade (mesmo que seja de violência) para outra que se desconhece ou que não se pretende conhecer?

\section{O CUIDADO DE SI POR MEIO DO DIÁLOGO}

Tomando como ponto de partida o cuidado de si como a forma mais autêntica do indivíduo permitir conhecer a si mesmo é necessário que se dedique a esta tarefa árdua de consagrar alguns momentos a voltar-se para si. Entretanto, é preciso tempo para que isso se fixe no decorrer da vida ou do dia para consagrá-la.

Por vezes, a idéia de o ser humano se reconhecer como cuidador de si parece ser óbvia, contudo, comumente pode se tornar uma tarefa esquecida, anulada ou atribuída a outrem, sendo neste último caso, uma das razões pelas quais, freqüentemente, as expectativas deste cuidado não são supridas.

As mulheres inseridas no contexto de violência doméstica, ao queixarem-se diversas vezes na Delegacia de Proteção à Mulher contra agressões físicas e/ou ameaças pelos parceiros, podem estar imputando momentaneamente a esta instituição a autonomia para que decida por suas ações. Entretanto, quando tal instituição impõe uma decisão por parte destas mulheres - diante do que desejam que seja efetuado a partir das queixas prestadas - muitas delas desistem da obrigação de atuar, justificando-se pelo medo das posteriores ameaças pelos parceiros devido às queixas ou pela culpa, da qual porventura poderá surgir se acontecer algo desagradável ao parceiro. Deste modo, ausentam-se da responsabilidade para consigo, e ao mesmo tempo sofrem por não tomar as decisões que irão lhes proporcionar a mudança, desencadeando um ciclo vicioso retornando às mesmas queixas de agressões e/ou ameaças.

Um dos motivos pelos quais mulheres inseridas no contexto de violência doméstica, tornarem-se passivas diante da resolução das suas questões de sofrimento, pode ser atribuído ao fator violência estar presente cotidianamente, trazendo conseqüências demasiadamente destrutivas para o bem-estar geral desta mulher, a ponto de abalar o fator mais genuíno da essência da condição humana, identificado como "a fortaleza para enfrentar um conflito"(21:10). Estas explanações podem ser contextualizadas pela história de vida compartilhada por Laura que, apesar de já no segundo encontro reflexivo ter mudado de domicílio, seu marido ainda exercia sobre ela o controle emocional, se apropriando de todo o dinheiro que a mesma ganhava. Ela não conseguia, dessa maneira, se desvencilhar das ameaças e, por conseguinte, permanecendo com um dos grandes fatores de risco que a conduzia a ingerir álcool, que era o subjugamento à violência psicológica. 
O ser humano submetido constantemente a qualquer tipo de violência torna-se provavelmente não só passivo diante das suas questões de sofrimento, como também, exime-se de sua responsabilidade com o seu corpo e com a sua saúde. A violência representa um grande risco para a realização do processo vital humano, pois ele ameaça a vida, altera a saúde, produz doenças e provoca a morte, como realidade ou como possibilidade ${ }^{(2)}$.

A violência em todos os seus seguimentos abala a capacidade do ser humano de compreender e interpretar sua situação e sua condição (física, mental, social, cultural, histórica) e de agir tendo em vista fins escolhidos por sua própria deliberação e decisão. $\mathrm{O}$ exposto acima pôde ser comprovado com a experiência de vida compartilhada por Ana, esclarecedora no que diz respeito aos resultados de um indivíduo passar anos num contexto de violência intrafamiliar. As conseqüências podem ser devastadoras, culminando em graves desequilíbrios emocionais, dores crônicas pelo corpo e uso abusivo de medicamentos.

Para que um indivíduo consiga enfrentar os conflitos que surgem na trajetória de sua existência é preciso identificar-se como um ser autônomo, uma unidade diferenciada de todos os outros seres humanos, principalmente no que concerne aos seus desejos, escolhas e ações. Pode-se atribuir o diálogo com outrem uma das maneiras mais importantes da atividade consagrada a si mesmo, uma vez que ela não constitui um exercício da solidão, mas sim uma verdadeira prática social.

É preciso que o diálogo seja o compartilhamento, respeito e mobilização cultural de desejos e interesses, particularmente daqueles que se encontram em torno da busca do bem-estar biopsicossocial. Mais que a idéia de método e técnica, o diálogo em saúde deve ser considerado como síntese do ato interativo, como autêntica relação em base humanizada, pois o diálogo se impõe como caminho pelo qual os homens ganham significação enquanto homens; é o encontro em que se solidarizam o refletir e o agir de seus sujeitos endereçados ao mundo a ser transformado e humanizado ${ }^{(23)}$.

Apesar de este processo mútuo parecer simples, ele somente pode ocorrer em situações de prática que "sejam intencionais"(24:42). Para a realização do resgate do "cuidado de si" com estas mulheres foi preciso compreender suas dificuldades em verbalizar uma demanda terapêutica, sendo que na origem destas dificuldades, pode estar o vínculo estabelecido com o homem autor da agressão.

\section{CONSIDERAÇÕES FINAIS}

Os encontros reflexivos com as mulheres inseridas no contexto de violência doméstica proporcionados com o objetivo de desenvolver uma ação preventiva seletiva ao abuso de drogas foi essencialmente uma prática para o desenvolvimento da capacidade de autocuidado com as mesmas. Incentivouas o desenvolvimento do hábito de refletirem sobre o contexto, sobre seus comportamentos, emoções e cognições associadas à violência no lar e às drogas, a fim de que iniciassem um pensamento crítico diante das suas questões de sofrimento evidenciado ao retornarem três ou mais vezes à Delegacia de Proteção à Mulher, solicitando ajuda com o intuito de cessar o tormento diante das ameaças e/ou agressões físicas por parte do parceiro. Como também, diante da responsabilidade com os seus corpos e com a saúde, resgatando, por assim dizer, a habilidade intrínseca de todo o ser humano que é o "cuidado de si".

No desenvolvimento da prática do "cuidado de si" por meio do diálogo, o conhecimento de si ocupa um lugar considerável. Na essência, o cuidador participa de um diálogo reflexivo na experiência compartilhada de vida do ser cuidado, desenvolvendose a relação entre ambos, que, por sua vez inclui uma abertura, uma receptividade ao outro.

Essa tecnologia - o diálogo (traçada como procedimento sistemático e/ou experiência prática) é imprescindível para o resgate da dimensão corporal subjetiva, mas também do processo de emancipação de preceitos de sujeição da vida, em prol da cidadania ${ }^{(25)}$.

Considerando que a violência doméstica possa ser um fator de risco para o abuso de substâncias psicoativas, especialmente por mulheres submetidas às agressões neste contexto, buscou-se proporcionar às mulheres - a partir de suas verbalizações e a conseqüente escuta dos seus discursos - a identificação das conseqüências do risco, ou seja, as conseqüências prejudiciais da violência doméstica em sua saúde, como também, incentivar as mulheres a reconhecer/identificar as situações onde a ingestão de substâncias psicoativas possa ocorrer e as funções que são atribuídas à droga nessas situações.

\section{REFERÊNCIAS}

1 Forattini OP. Pesquisa em saúde pública. Rev Saúde Publ. 1995 Abr;29(2):81-8. 
2 Minayo MCS. The difficult and slow inclusion of violence on the health sector agenda. Cad Saúde Públ. 2004 Mai/Jun;20(3):646-7.

3 Deslandes SF. O atendimento às vítimas de violência na emergência: prevenção numa hora dessas? Ciênc Saúde Coletiva.1999;4:81-94.

4 Blanco P, Ruiz-Jarabo C, Garcia de Vinuesa L. et al. La violencia de pareja y la salud de las mujeres. Gac Sanit. [periódico na Internet]. Mai 2004 [acesso 2005 Mai 10], 18 (supl.1):182-8. Disponível em http://scielo.isciii.es.

5 Heise L, Pitanguy J, Germain A. Violencia contra la mujer: la carga oculta sobre la salud. Washington DC: Organización Panamericana de la Salud/ Organización Mundial de la Salud; 1994.

6 Schraiber LB, d'Oliveira AFPL, Franca-Junior I, Pinho AA. Violence against women: a study in a primary healthcare unit. Rev Saúde Públ. 2002 Ago; 36(4):470-7.

7 Erdmann AL. O sistema de cuidados de enfermagem: sua organização nas instituições de saúde. Texto Contexto Enferm. 1998; Mai/Ago:7(2):52-69.

8 Jorge MHPM, Laurenti R. Apresentação. Rev Saúde Públ. 1997;31(4 Suppl):01-4.

9 Pereira CA, Silva CJ. Conceitos e práticas em prevenção. Anais XV Congresso da Associação Brasileira de Estudos do Álcool e outras Drogas (ABEAD). São Paulo, 2003.

10 Silva LJ. Public health and social responsability. Rev Saúde Públ. 2002 Ago;36(4)suppl:1

11 Bardin L. Análise de conteúdo. Lisboa: Edições 70; 1977.

12 Formigoni MLOS et al. A intervenção breve na dependência de drogas - a experiência brasileira. São Paulo: Contexto; 1992.

13 Breda MZ, Augusto LGS. Health care given to people suffering of mental disorders assisted by basic health attention. Ciênc Saúde Coletiva. 2001;6(2):471-80.

14 Lupton D. Corpo, prazeres e práticas do eu. Educação e Realidade. 2000 Jul/Dez;25(2):15-48.

15 Mandú ENT. Inter-subjectivity on the qualification of health care. Rev Latino-Am Enferm. 2004;Jul/Ago 12(4):665-75.

16 Xavier C, Guimarães C. Uma semiótica da integralidade: o signo da integralidade e o papel da comunicação. In:
Pinheiro R, Mattos RA, organizadores. Cuidado: as fronteiras da integralidade. Rio de Janeiro: Hucitec: ABRASCO. 2004: 133-55.

17 Nascimento AL, Lacerda MR, Maftum MA. Cuidado transpessoal de enfermagem no domicílio ao portador de transtorno mental e sua família. Cogitare Enferm. 2006;(1):8-15

18 Menezes TC, Amorim MMR, Santos LC. Domestic physical violence and pregnancy: results of a survey in the postpartum period. Rev Bras Ginecol Obstet [periódico na Internet]. 2003 Jun [acesso em 2005 Aug 18] 25(5):309-16. Disponível em http://www.scielo.br

19 Maldonado M. Casamento: término e reconstrução. São Paulo: Saraiva; 1995.

20 Colasanti M. E por falar em amor. São Paulo: Círculo do Livro; 1987.

21 Travelbee J. Intervencion em enfermeria psiquiátrica: el processo de la relacion de persona a persona. Colômbia: Carvajal S.A.; 1979.

22 Agudelo SF. La violencia: un problema de salud pública que se agrava en la región. Bol Epidemiol OPS. 1990; 11:01-7.

23 Freire P. Pedagogia do oprimido. $17^{\mathrm{a}}$ ed. Rio de Janeiro: Paz e Terra; 1987.

24 Boykin A. A enfermagem como conforto: o artístico no cuidado. Texto Contexto Enferm. 1998 Mai/ Ago;7(2):36-51.

25 Mandú, ENT. Dimensões político-éticas na atenção básica à saúde sexual e reprodutiva em Cuiabá [tese]. Ribeirão Preto (SP): Escola de Enfermagem. Universidade de São Paulo; 2002. 